\title{
Novel Sulfonated Ethylene/1-Octene Copolymer Ionomer Nanocomposite: Synthesis and Properties
}

\author{
Sharmila Pradhan ${ }^{1,2}$, Stefanie Scholtissek ${ }^{3}$, Ralf Lach ${ }^{4,5}$, Werner Lebek ${ }^{3}$, \\ Wolfgang Grellmann ${ }^{4,5}$, Goerg H. Michler ${ }^{3}$ Rameshwar Adhikari ${ }^{1,2, ~ *}$ \\ ${ }^{1}$ Central Dept. of Chemistry, Tribhuvan University, Kathmandu, Nepal, ${ }^{2}$ Nepal Polymer Institute (NPI), \\ P. O. Box 24411, Kathmandu, Nepal, ${ }^{3}$ Institute of Physics, Martin Luther University, Halle-Wittenberg, \\ Germany , ${ }^{4}$ Institut für Polymerwerkstoffe (IPW) e.V., Merseburg, Germany, ${ }^{5}$ Centre of Engineering, \\ Martin Luther University Halle-Wittenberg, Halle/Saale, Germany.E mail: nepalpolymer@yahoo.com
}

\begin{abstract}
The nanocomposites based on sulfonated ethylene/1-octene copolymer (sEOC) and organophilic modified layered silicate were synthesized. The morphology of the ionomeric product was studied with the help of Scanning Electron Microscopy (SEM), Atomic Force Microscopy (AFM), Fourier Transform Infrared (FTIR) spectroscopy and microhardness measurements. It was shown that via the solution cast technique, the nanocomposite with uniformly distributed filer morphology can be conveniently prepared. The significant enhancement of the mechanical properties due to ionomerization was attested with the help of depth sensing microhardness measurements. It was found that the hardness of ionomer nanocomposite comprising $5 \mathrm{wt.}$-\% layered silicate is approximately four fold of the neat elastomer.
\end{abstract}

Keywords: Ethylene/1-octene copolymer, sulfonation, microhardness, nanocomposite, microhardness, electron microscopy

\section{Introduction}

One of the recent trends in developing advanced materials is to use simple routes such as chemical modification of existing polymers which alters the structure and physico-mechanical properties ${ }^{1}$. Many research works are concerned with the ionomeric modification of the polymers ${ }^{2}$. Generally the ionomers containing few ionic groups $(<10 \mathrm{~mol} \%)$ which are responsible for the dramatic improvements of mechanical properties including tensile strength, elasticity, modulus, abrasion resistance through ionic interactions as well as that of electrical and solvent uptake properties etc ${ }^{3,4}$. Thus chemically modified polymers have wide range of applications such as in electrochemical, petrochemical and biotechnical fields ${ }^{5}$.

Several researchers have modified different classes of polymers by sulfonation. For instance, Turbak was one of the first scientists who carried out the sulfonation of macromolecules such as polystyrene (PS) using triethyl phosphate and sulfur trioxide as sulfonating agents in dichloroethane ${ }^{6}$. Polystyrene was also sulfonated by Makowski using acetyl sulfate complexes as sulfonating reagent in a solution of dichloroethane, which generates random functionalities along the polymer backbone without significant degradation or cross-linking of the reaction products ${ }^{7}$. Later Cristiane et al. functionalized polystyrene in pilot plant scale with varied sulfonation degrees as the sulfonated products are extremely used in many industrial applications, for example, compatibilizing blends of immiscible polymers, in ion exchange materials, membranes for reverse osmosis and ultrafiltration, as plasticizers for macro-defect-free

\section{*Corresponding author}




\section{J. Nepal Chem. Soc., vol. 28, 2011}

concrete and conductive composites ${ }^{8}$. The details of the sulfonation reaction, along with thermal, physical properties of modified polystyrene as well as interactions present in sulfonated PS and pure PS including cross-linking $\mathrm{PS}_{-} \mathrm{SO}_{3} \mathrm{H}$ can be found in the literature ${ }^{9}$. Moreover several papers related to sulfonation of rubber like polymers have been published. For instance, Xie et al. investigated several properties like melt flow, solution viscosity, and mechanical properties of polar functionalized styrene-butadiene-styrene (SBS) triblock copolymer which has significant applications like adhesives for polar substances and compatibilizers for blends of polar and non-polar polymers ${ }^{10}$.

Picchioni et al. sulfonated vinyl aromatic polymers such as polystyrene and styrene-ethylene/ butylenes-styrene (SEBS) block copolymer via the procedure suggested by Weiss R.A et al. and the sulfonated polymers were blended with styrene-butadiene-styrene (SBS) copolymer in a Brabender mixer in order to sulfonate SBS. The sulfonation method adopted by Picchioni was suitable for modifying SBS which is generally not selective towards benzene ring due to presence of highly reactive double bonds. Their literature showed that the compatibility between the components and improvements of thermal behavior of the blends were controlled by low sulfonation degree value and strong counter-ion $\left(\mathrm{K}^{+}\right)$. Similarly the aluminum and zinc salt of sulfonated SEBS and PS improved the thermal behavior significantly as well as complete miscibility of sulfonated component in SBS domains ${ }^{11}$.

Xie et al. studied about the favorable conditions for carrying out the sulfonation in highly unsaturated macromolecule like SBS triblock copolymer without gelation as the polymers of high degree of unsaturation undergo gelation creating problems during sulfonation ${ }^{12}$. Along with the suitable conditions, the melt flow, solution viscosity and mechanical properties of the polar functionalized SBS were also investigated. Xie et al. also reported the enhancement in mechanical properties of polar functionalized SBS compared to pristine polymer and illustrated the decreasing ionic potential of mono valent and divalent cations present in the corresponding salt of ionomer decrease the melt viscosities ${ }^{12}$.

Metallocene catalyst based poly(ethylene-styrene) (ES) random copolymer is one of the newly developed thermoplastic elastomer which was used for partial functionalization through sulfonation and to compare the thermal properties like glass transition temperature, melt viscosity and rubbery modulus by Shim and Weiss ${ }^{13}$. Their work disclosed that the lightly sulfonated ES (ran) copolymer has lower glass transition temperature than virgin ethylene-styrene random copolymer (ES) because of lower crystallinity whereas the glass transition temperature, melt viscosity and rubbery modulus of neutralized product of sulfonated ES was found to be higher with respect to the base polymer (ES) which made them better thermoplastic elastomer to use extensively in filled system, injection molding and blends ${ }^{13}$.

Xie et al. ${ }^{14}$ performed the synthesis of the sulfonated styrene-butadiene-styrene (SBS) via epoxidation followed by ring opening reaction and studied some properties like oil and water absorbency, dilute solution properties and mechanical properties. In addition to this, the compatibilizing effect of the blends of ionomer and polypropylene for blending SBS with oil resistant non thermoplastic chlorohydrins rubber has been investigated. They explained that the greater concentration of ionic group increases the water absorbency and dilute solution properties due to ion dipole interactions but decreases the oil absorbency. At the same time, the sodium ionomers of SBS were found to have higher tensile strength and ultimate elongation compared to that of parent SBS. A compatibilizing effect of the ionomer has been shown in blends containing equal amount of SBS and oil resistant chlorohydrins rubber. The mechanical properties and solvent resistance has been found to be much better in the blend containing $3 \%$ ionomer than the blend without ionomer ${ }^{14}$.

Vulcanized ethylene-propylene-diene [EPDM] terpolymer has been grafted with sulfonic group at maximum degree by Barroso et al. maintaining the optimum conditions with respect to solvent type, reaction time, concentration of acetyl sulfate and film thickness. The procedure was a novel one as the pre-dissolution of polymer was not required. This method is of great significant as it could be conveniently applied in industrial processing ${ }^{15}$. 
Nowadays, several research works have been carried out in the base polymer like poly ethylene/1octene copolymer (EOC) elastomers because of its uniform distribution of co-monomer content and narrow molecular weight distribution ${ }^{16}$. However these elastomers were forbidden to use in many applications for being non-polar character hence elastomeric EOC was conveniently modified through the grafting of acrylic acid ${ }^{17}$ and sulfonation ${ }^{18}$ which change hydrophobic polymers into hydrophilic one and enhance significantly the oil resisting property, adhesive properties, tensile strength, elastic modulus, abrasion resistance and make better compatible with polar polymers, fillers like silica ${ }^{17,18}$. It has been found that the sulfonation of EOC leads to the formation of low cost, durable proton conducting membrane (PEM) which is extremely useful in fuel cell application.

The sulfonation not only improves the physico-mechanical properties, it also brings some important disadvantages such as decrease in overall material strength and toughness along with thermal stability because of low crystallinity and early degrading property of grafted free polar units from elastomeric macro-chains ${ }^{18}$. However, these properties have been overcome incorporating ionic crosslinks via neutralization of the sulfonic acid group of the modified elastomers which are thus extremely used as golf ball cover membranes and food packaging materials and adhesives.

The present work aims at preparation of ionomers incorporating sulfonic acid group in commercially available ethylene/1-octene copolymer (EOC) elastomer and to investigate the influence of ionomeric modification of an EOC grade by nanofiller on its morphology and microhardness behavior.

\section{Experimental Methods}

\section{Materials and Sample preparation}

Ethylene/1-octene copolymer (EOC), Affinity EG8150 grade manufactured from Dow chemical company having molecular weight $161,400 \mathrm{gm} / \mathrm{mol}$, and melt flow index (MFI) of $0.5 \mathrm{gm} / \mathrm{min}$ was used as matrix. Degree of crystallinity of the EOC is $16 \%$ and co-monomer content is $39 \%$. The molecular structure of EOC is as shown in scheme 1.

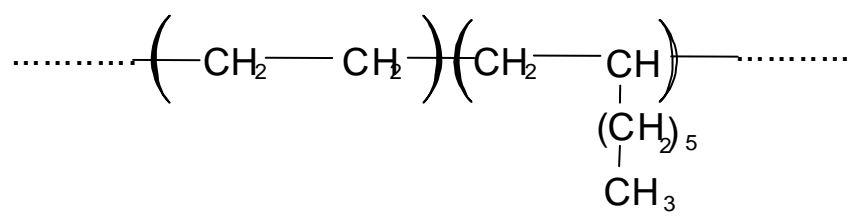

Scheme 1. Schematic representation of the ethylene/1-octene copolymer

Organically modified layered silicate (LS), called Nanofil 5 manufactured by Südchemie, Munich, Germany was used as nanofiller. The LS represents 2D filler. The polymer and the filler were kindly supplied by the respective manufacturers. Chloroform, toluene sulfuric acid, acetic anhydride, methanol used was purchased from local market and was used as received.

The ionomer precursor was prepared from the EOC by the action of acetyl sulfate (AS) produced by the reaction of acetic anhydride and concentrated sulfuric acid (approximately 4:1 volumetric ratio). For preparation of acetyl sulfate, $10 \mathrm{ml}$ of chloroform was cooled to $0{ }^{\circ} \mathrm{C}$ in ice bath for 10 minutes which was then mixed with $4 \mathrm{ml}$ of acetic anhydride. After that $1 \mathrm{ml}$ of concentrated sulfuric acid was added 
slowly stirring the mixture for 10 minutes and finally the temperature of the acetyl sulfate solution was cooled to room temperature.

Five grams of EOC was dissolved in $100 \mathrm{ml}$ of chloroform in a $500 \mathrm{ml}$ three necked flask equipped with condenser. The solution was heated to $50{ }^{\circ} \mathrm{C}$ for $1 \mathrm{hr}$ to dissolve completely. Then $5 \mathrm{ml}$ of freshly prepared AS solution was added drop by drop into the reaction mixture in stirring condition. Then the mixture was refluxed for 3 hours on an oil bath preheated at $55^{\circ} \mathrm{C}$ for sulfonation reaction.

After complete heating the sulfonation reaction was terminated by adding $30 \mathrm{ml}$ of methanol. The white precipitate formed was washed with boiling water for $1 \mathrm{hr}$ at room temperature to get acid free product which was then air dried to constant weight and stored in desiccator containing $\mathrm{CaCl}_{2}$.

The ionomer nanocomposite containing 5\% wt layered silicate (LS) was prepared from ionomer precursor (sEOC) by solution casting method. The suspension of layered silicate (Nanofil 5) in toluene was mixed with the solution of sEOC prepared by dissolving fixed amount of sEOC in required volume of toluene. The mixture was subjected to ultrasonication for 30 minutes and afterwards the mixture was poured slowly into petri dish which was left for solvent evaporation for a week. The film thus was air dried till constant weight.

\section{Characterization Techniques}

The $-\mathrm{SO}_{3} \mathrm{H}$ group present in the sulfonated product is determined titrimetrically for which the calculated amount of the sample was dissolved in toluene/acetone mixture (9:1 volumetric ratio) and titrated against standard methanolic sodium hydroxide $(\mathrm{NaOH})$ solution using phenolphthalein as indicator. The sulfonation degree was calculated by the formula ${ }^{10}$,

$$
\text { Mequiv./100gm EOC }=100 * \mathrm{~N}_{\mathrm{NaOH}}\left(\mathrm{V}_{1}-\mathrm{V}_{0}\right) / \mathrm{W}
$$

where,

$\mathrm{N}_{\mathrm{NaOH}}=$ Normality of the methanolic $\mathrm{NaOH}$,

$\mathrm{V}_{1}=$ Volume. of $\mathrm{NaOH}$ consumed by the sEOC,

$\mathrm{V}_{0}=$ Volume of $\mathrm{NaOH}$ consumed by blank solution, and

$\mathrm{W}=$ Weight of the $\mathrm{sEOC}(\mathrm{g})$

From titration, the amount of sulfonic acid group present in modified EOC elastomers found to be 0.2 millequivalent per gram of the ionomer precursor. The degree of sulfonation was $6.5 \%$ by weight.

The samples were characterized by means of Fourier Transform Infrared (FTIR) spectroscopy (Bruker Optics GmbH, Germany) in transmission mode.

The fracture surface of each samples were studied by Scanning Electron Microscopy (SEM). Prior to SEM image, each fracture was sputter-coated with a thin layer (ca. $10 \mathrm{~nm}$ ) gold film so as to make the surface conducting as well as stable toward irradiation and to avoid surface charging. Detailed morphology of samples was inspected by Atomic Force Microscopy (AFM) operated in tapping mode (Multimode AFM, Digital Instruments Santa Barbara, CA).

Microhardness indentation tests were carried out to determine mechanical behavior using microhardness tester (Fischerscope, Helmut Fischer GmbH, Germany).The tester equipped with Vickers pyramid based diamond indenter with an included angle between non adjacent faces of the pyramid of $136^{\circ}$, was allowed to form indent at different locations so that load (P)-indentation depth (h) diagrams 
were measured at different locations. The experiment was carried out using maximum load of $300 \mathrm{mN}$ at room temperature. The average Martens hardness HM of each sample was determined by analyzing five $\mathrm{P}-\mathrm{h}$ diagrams per specimen.

$$
\mathrm{HM}=\mathrm{P}(\mathrm{h}) / \mathrm{As}(\mathrm{h})=\mathrm{P}(\mathrm{h}) / 26.4 \mathrm{~h}^{2}
$$

where, $A_{s}(h)$ is the surface area of the indenter penetrating beyond the zero point of the contact (with $\mathrm{P}$ in $\mathrm{mN}, \mathrm{h}$ in $\mu \mathrm{m}, \mathrm{HM}$ in MPa). Furthermore, the indentation modulus $\mathrm{E}_{\mathrm{IT}}$ according to ISO 15477 and the work done due to elastic and plastic deformation $\left(\mathrm{W}_{\mathrm{e}}\right.$ and to $\left.\mathrm{W}_{\mathrm{p}}\right)$, respectively, were measured.

\section{Results and Discussion}

The results of FTIR spectroscopy of the pure EOC and sulfonated EOC (sEOC) recorded in transmission mode are as depicted in Fig. 1.

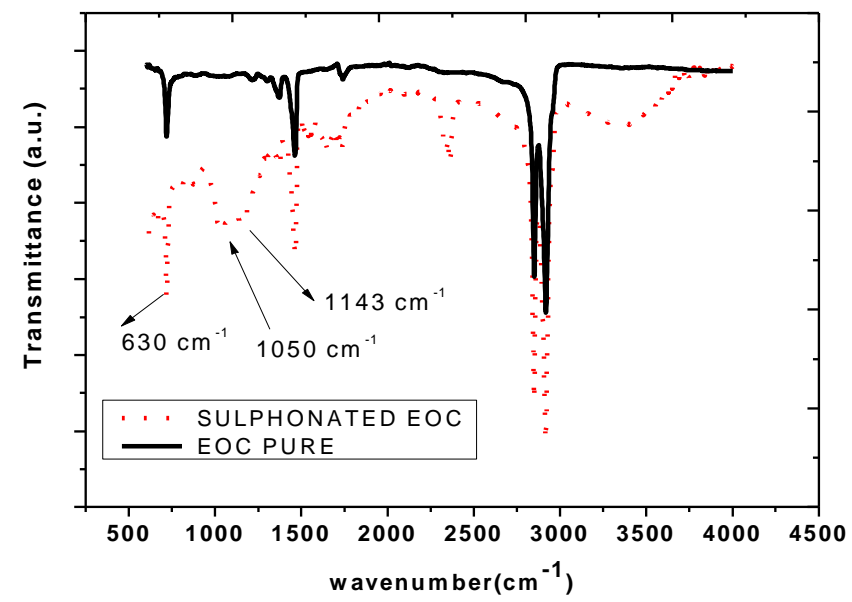

Figure 1. FTIR spectra of virgin EOC compared with that of ionomeric precursor, the SEOC.

Fig. 1 clearly shows the difference in the spectra of the pure polymer (EOC) and its ionomer precursor (sEOC). The peaks observed at 630 and around $1143-1170 \mathrm{~cm}^{-1}$ are assigned to the $\mathrm{C}-\mathrm{SO}_{3} \mathrm{H}$ and symmetric $\mathrm{SO}_{2}$ bond vibration respectively. The characteristic peak located at $1050 \mathrm{~cm}^{-1}$ can be assigned to the S-O stretching vibration of alkyl sulfonic group present in ionomeric precursor ${ }^{18}$. The results demonstrate that EOC has been successfully sulfonated under given experimental conditions.

The SEM micrographs of EOC and its ionomer nanocomposite (LS ionomer nanocomposite) are depicted in Fig. 2. The cryo-fracture surface of the sample was investigated by the SEM in so called secondary electron (SE) mode.

The SEM was used to observe the dispersion of filler particles in the sample. In Fig. 2 (left), the sample has nearly flat appearance which is due to the reversible deformation of the EOC rubber. In Fig. 2 (right), in addition, uniformly distributed bright flakes can be observed which are inorganic layered silicate particles having a width of several microns. Hence, the sample formed may not be purely nanocomposite, but partly a microcomposite. If the fillers were of nano-sized, they could not be visible in the SEM images owing to the low resolution capability of the SEM technique. Therefore, the samples were characterized by AFM in tapping mode using phase imaging (see Fig. 3). 

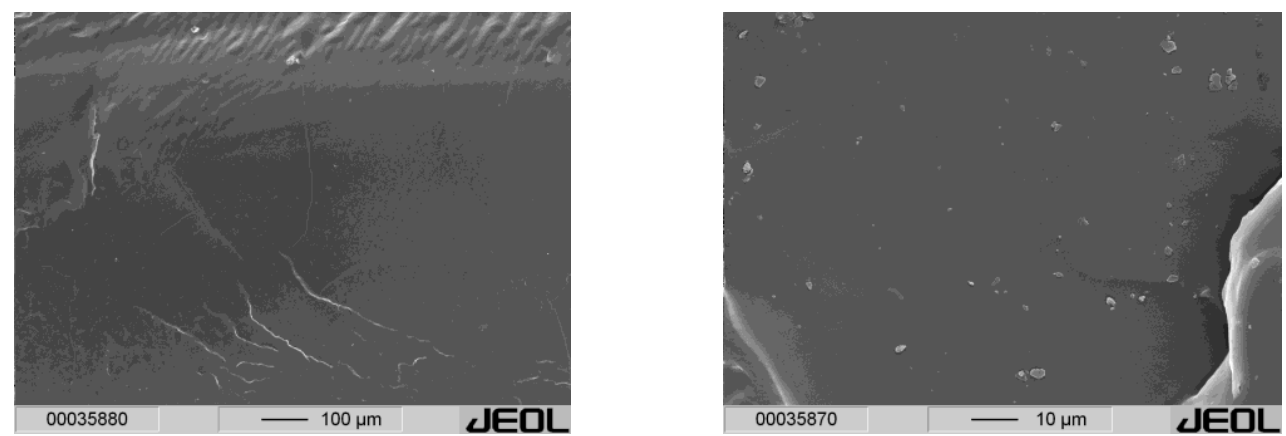

Figure 2. BSE mode SEM images of the fracture surfaces of the pristine EOC (left) and LS ionomer nanocomposite (right).

Fig. 3a reveals the surface morphology of pristine EOC containing short wormlike, crystalline domains. Well developed lamellae are not visible. In case of sEOC (see fig $3 \mathrm{~b}$ ), even the domain observed in neat EOC cannot be recognized. The morphology is homogeneous. It implies that the sulfonation of the elastomer has drastically hindered the crystallization processes of the EOC elastomer.
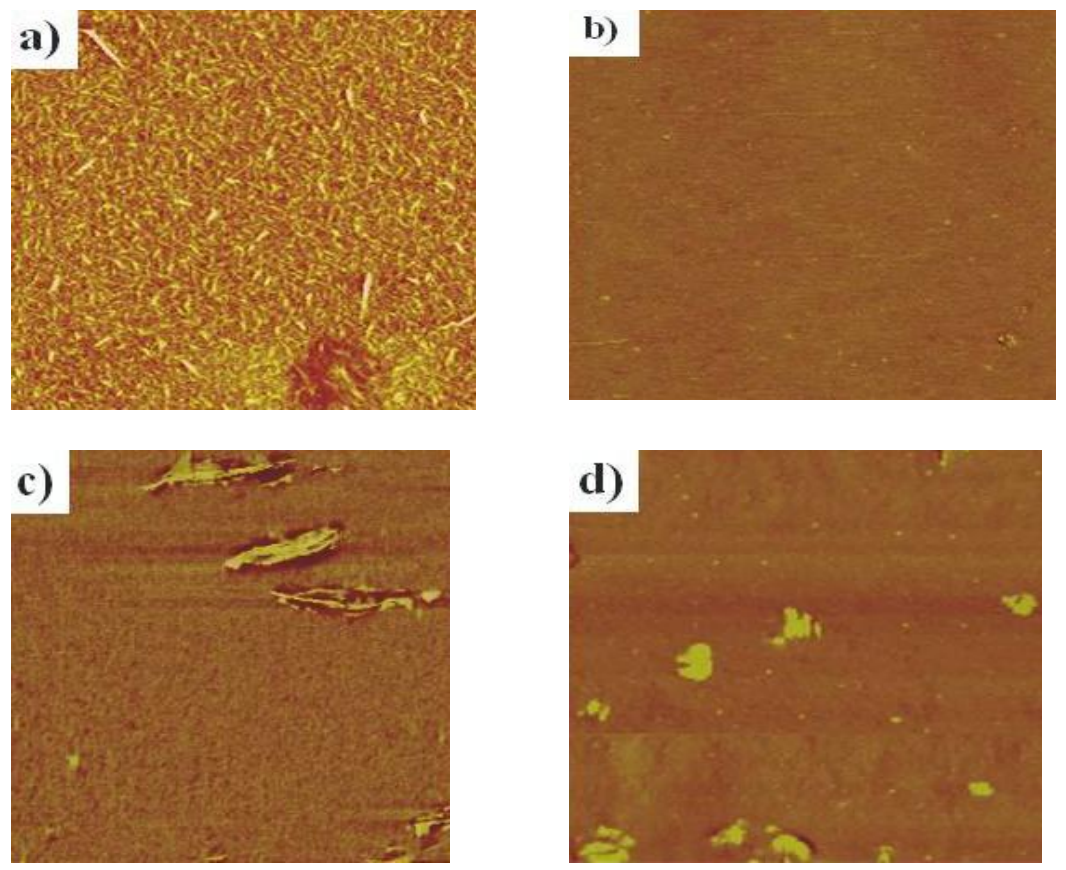

Figure 3: AFM phase images of a) EOC (surface), b) sEOC (surface), c) LS-ionomer (surface) and d) ionomer nanocomposite ( bulk); $3 \mu \mathrm{m} \times 3 \mu \mathrm{m}$ scans each.

In Fig. 3c-d the AFM images of LS ionomer nanocomposite film surface and bulk are presented. For the bulk structure imaging the sample was ultramicrotomed under liquid nitrogen and the freshly sectioned surface was studied by the AFM. The surface morphology of the ionomer nanocomposite (Fig.3c) contains evenly distributed with white stacks of layered silicate. In some parts, individual 
nanolayers can be seen as well. The homogeneously distributed tactoids of nanoparticles with diameter up to $300 \mathrm{~nm}$ are captured in the AFM image of bulk of the ionomer nanocomposite (see Fig. 3d).

As microhardness is related to mechanical behavior of the material, elastic modulus can be calculated from the microhardness measurements. The indentation or elastic modulus is one of important parameter to determine the stiffness of the material. The results of the microhardness test of the investigated samples are presented in the form of load (P)-indentation depth (h) curves consisting of loading and unloading parts as shown in Fig. 4. From maximum load and the initial part of the unloading curve, the properties like Martens hardness (or universal hardness) and indentation modulus, respectively, can be evaluated.

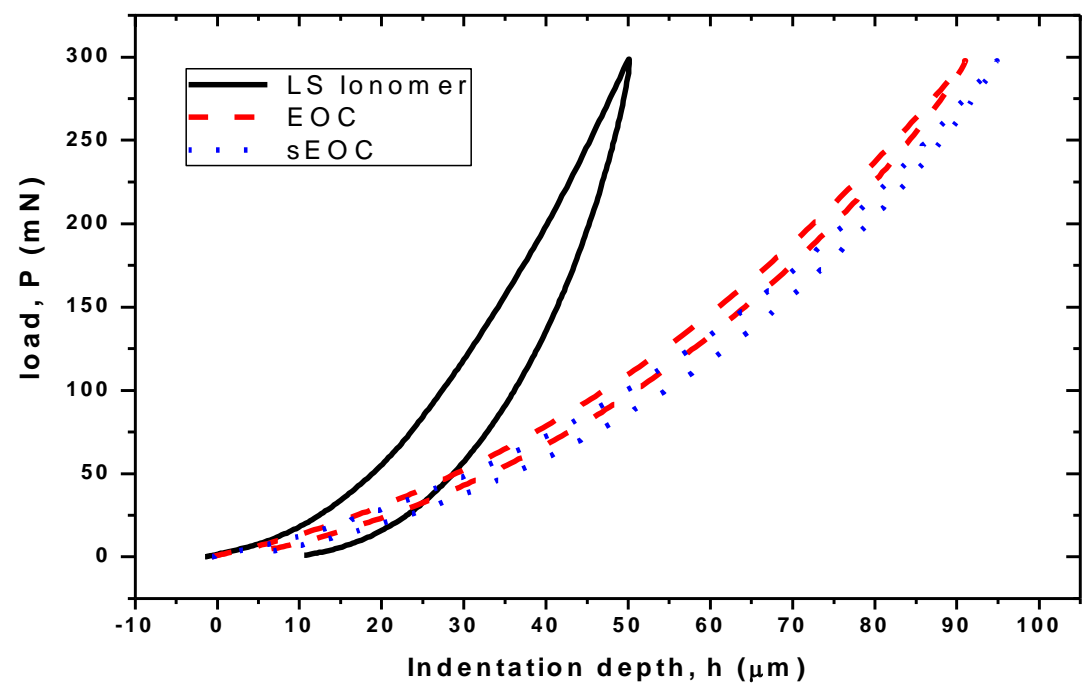

Figure 4: Load versus indentation depth $(P-h)$ curves of the samples EOC, sEOC and sEOC-LS ionomer.

From the P-h diagrams presented in Fig. 4, it can be observed that the slope of unloading curve of sEOC lower than that of EOC indicating that $\mathrm{SEOC}$ is softer than EOC probably due to ionic interaction of $-\mathrm{SO}_{3} \mathrm{H}$ group with the matrix. Upon ionomeric nanocomposite formation with $5 \mathrm{wt}$. $\%$ layered silicate (LS), the slope of the unloading curve dramatically increases as shown in Fig. 4, implying a dramatic increase in hardness and plasticity of the sample.

Table 1 collects Martens hardness (HM), indentation modulus $\left(\mathrm{E}_{\mathrm{IT}}\right)$ and the ratio of $\mathrm{W}_{\mathrm{e}}$ (work done due to elastic deformation) to $\mathrm{W}_{\mathrm{p}}$ (work done due to plastic deformation) of the samples determined by microhardness measurement. The Martens hardness and indentation modulus of sEOC is lower than that of pure EOC. Hence it proves that sEOC behaves in more elastomeric manner than the pristine EOC which might be attributed to reduction of crystallinity (compare Fig. 3a and 3b). This fact is further confirmed by the increment of the ratio of $\mathrm{W}_{\mathrm{e}} / \mathrm{W}_{\mathrm{p}}$ of the sEOC with respect to EOC (See Table 1), which implies that the elastic work of deformation, characteristic of rubbery materials, increases on sulfonation of the pristine EOC. However, upon ionomeric modification of sEOC with $\mathrm{Na}^{+}$of Nanofil 5 (LS), the mechanical behavior, for example Martens hardness, indentation modulus and the plastic work of sEOCLS ionomer is found be enhanced due to the physical cross-links through ionic associations. It should be noted that hardness of the ionomer nanocomposite is approximately three times that hardness of the pure EOC due to addition of only $5 \mathrm{wt} .-\%$ of the layered silicate, a remarkable enhancement in the mechanical properties. Obviously, there is a parallel loss in elastomeric property as shown by the reduction in the ratio $\mathrm{W}_{\mathrm{e}} / \mathrm{W}_{\mathrm{p}}$ due to formation of nanocomposite which shows more plasticity than the neat EOC. 
Table1: Characteristic average mechanical parameters of the samples determined by microhardness measurements

\begin{tabular}{llll}
\hline Samples & $\mathrm{HM}(\mathrm{MPa})$ & $\mathrm{E}_{\mathrm{IT}}(\mathrm{MPa})$ & $\mathrm{W}_{\mathrm{e}} / \mathrm{W}_{\mathrm{p}}$ \\
\hline EOC & 1.68 & 24.1 & 8.1 \\
sEOC & 1.28 & 18.3 & 10.1 \\
Ionomer & 4.48 & 76.5 & 1.7 \\
\hline
\end{tabular}

$\mathrm{HM}$ - Martens Hardness (or universal hardness); $\mathrm{E}_{\mathrm{IT}}$ - indentation modulus, $\mathrm{W}_{\mathrm{e}}$ - total elastic work of deformation and $\mathrm{W}_{p}$ - total plastic work of deformation

\section{Conclusion}

A new type of ionomer and ionomeric nanocomposites of metallocene based ethylene/1-octene copolymer (EOC) and organophilic layered silicate nanocomposite was successfully synthesized via sulfonation followed by solution casting method. On the basic of results obtained from SEM, AFM and microhardness measurements, it was demonstrated that the ionomeric nanocomposite has significantly improved mechanical plasticity compared to the corresponding virgin elastomer which can be attributed to the formation of strong secondary crosslinks in nanometric domains. For example, Martens hardness of ionomer nanocomposite was $4.48 \mathrm{MPa}$ compared to $1.28,1.68 \mathrm{MPa}$ respectively for ionomer precursor and neat EOC elastomers. Similar trend was observed for indentation modulus of the samples. The ionomeric modification improved the elastomeric property while the nanocomposite showed enhanced plastic deformation.

\section{Acknowledgements}

The authors are very thankful to German Science Foundation (DFG) for providing financial support to S.P.A. to visit Martin Luther University Halle-Wittenberg, Germany. Nepal Academy of Science and Technology (NAST) is acknowledged for providing PhD fellowship to SPA. Further Dr. P. N. Yadav and Dr. M. R. Pokharel (both from Central Department of Chemistry, Ttribhuvan University, Kathmandu) are thanked for providing A. R. grade chemicals for synthesis and for carrying out some FTIR measurements.

\section{References}

1. J. J. Meister, Polymer Modification-Principles, Techniques and Applications; CRC Press, N.Y, 2000.

2. K. Wakabayashi and R. A. Register, Macromolecules, 2006, 39, 1079.

3. W. J. Macknight and T. R. Earnest, J. Polym. Sci. Part D: Macromol. Rev., 1981, 16, 41.

4. A. Eisenberg and M. King, Ion-Containing Polymers: Physical Properties and Structure; Academic Press, New York, 1977.

5. A. D. Wilson, Developments in Ionic Polymers; Applied Science Publishers, London, 1983.

6. A. F. Turbak, Ind. Eng. Chem. Prod. Res. Dev., 1962, 1, 275.

7. H. S. Makowski, R. D. Lundberg and G. H. Singhal, US pat. $3870841,1975$.

8. Y. Fu and R. A. Weiss, Synth. Met. 1997, 84, 103.

9. C. R. Martins, G. Ruggeri and M. A. De Paoli, J. Braz. Chem. Soc., 2003 14, 797.

10. H. Q. Xie, D. G. Liu and D. Xie, J. Appl. Polym. Sci,. 2005. 96, 1398.

11. F. Picchioni, I. Giorgi, E. Passaglia, G. Ruggeri and M. Aglietto, Polym. Int. 2001, 50, 714

12. H. Q. Xie, D. G. Liu and D. Xie, J. Appl. Polym. Sci., 2005, 96, 1398.

13. S. Y. Shim, and R. A. Weiss, Polym. Int., 2005, 54, 1220.

14. H. Q. Xie, Y. G. Yu, G. Y. Liao, W. Yang and D. Xie, J. Elast. plast., 2007, 39, 317.

15. F. Barroso-Bujans, R. Verdejo, A. Lozano, J. L. G. Fierro and M. A. Lopez- Manchado, J. Acta Materialia, $2008, \mathbf{5 6}, 4780$.

16. Y. C. Hwang, S. Chum, K. Sehanobish, Annu. Tech. Conf, 1994, 94, 3414.

17. A. Biswas, A. Bandhyopadhyay, N. K. Singha and A. K. Bhowmick, J. Appl. Polym. Sci., 2009, 114, 3906.

18. A. Biswas, A. Bandhyopadhyay, N. K. Singha and A. K. Bhowmick, J. Mater. Sci., 2009, 44, 3125. 